typical periventricular calcified lesions. No cardiac tumours were visible echocardiographically.

The parents were counselled that a future child was at a 1 in 2 risk of being affected by tuberous sclerosis, but that the manifestations of this were very variable. However, the mother unintentionally became pregnant soon afterwards and was offered fetal cardiac ultrasonography as a possible method of antenatal prediction of an affected child. Fetal echocardiography was performed on two occasions during the second trimester. The fetal heart was examined initially at 18 weeks' gestation and appeared normal. A second examination of the fetal heart during the 22nd week of pregnancy revealed the presence of a large tumour within the body of the right ventricle and at least one tumour on the surface of the heart (figure). As this fetus was almost certainly affected by tuberous sclerosis, termination of the pregnancy was offered. Necropsy confirmed the presence of a rhabdomyoma filling the body of the right ventricle with multiple smaller tumours in the left ventricle and on the external surfaces of the heart.

\section{Discussion}

The gene for tuberous sclerosis is notoriously variable in its expression. The frequency of associated rhabdomyomata large enough for echocardiographic detection is unknown. The family described may be unusual in that three out of four affected family members had echocardiographically detectable cardiac tumours. The tumours were large enough to cause circulatory obstruction in two of the four. Finding no evidence of cardiac tumours would not have excluded the diagnosis of tuberous sclerosis in this case, but the positive identification of a cardiac tumour indicated a third affected child $\overrightarrow{\bar{N}}$ in this family. Even in the absence of a family $\overrightarrow{0}$ history, a cardiac tumour in any patient found $\frac{C}{0}$ histologically to be a rhabdomyoma implies the $\overline{\frac{\sigma}{\sigma}}$ diagnosis of tuberous sclerosis whether that disease $\vec{\nabla}$ is clinically manifest or not. ${ }^{3}$

The fetal heart can be well visualised echocardio- $ळ$ graphically between 16 weeks' gestation and term. ${ }^{4} \overrightarrow{0}$

As this case shows, cardiac tumours can be $\overrightarrow{-}$ detected as a marker for tuberous sclerosis. As the $\bar{\omega}$ technique gives rise to no fetal or maternal discomfort it should be offered for possible antenatalç diagnosis in a pregnancy known to be at risk, i although the absence of visible cardiac lesions ${ }_{-}$ would not exclude the presence of the disease. It is $\dot{\omega}$ possible that in the future detailed ultrasonography

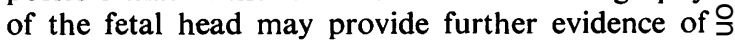
the disease when it is present.

\section{References}

1 Bohm N, Krebs G. Solitary rhabdomyoma of the heart: clinically silent case with sudden, unexpected death in an $\infty$ 11-month-old boy. Eur J Pediatr 1980;134:167-73.

2 Allan LD, Joseph MC, Tynan M. Clinical value of echocardiographic colour image processing in two cases 0 of primary cardiac tumour. Br Heart $J 1983 ; 49: 154-6$.

3 Davies MJ. Tumours of the heart and pericardium. In: Pomerance A, Davies MJ, eds. The pathology of the heart. London: Blackwell, 1975:423-40.

4 Allan LD, Tynan M, Campbell S, Anderson RH. Normal $\varrho$ fetal cardiac anatomy -a basis for the echocardio- $\overrightarrow{\bar{A}}$ graphic detection of abnormalities. Prenatal Diagnosis $1981 ; 1: 131-9$.

Correspondence and requests for reprints to Dr D C Crawford, Department of Paediatrics, Guy's Hospital, London SE1 9RT.

\title{
Unusual ocular findings in an infant with cri-du-chat syndrome
}

\author{
SOFIA KitSiOU-TZELI*, H D DELLAGRAMMATICAS*, C B PAPAS*, \\ I D LADAS †, AND C S BARTSOCAS* \\ *Second Department of Pediatrics, University of Athens, 'P and A Kyriakou' Children's Hospital; and \\ $\dagger$ Department of Ophthalmology, University of Athens, Greece.
}

SUMMARY A newborn male with cri-du-chat syndrome, congenital nuclear cataracts, microspherophakia, and probably ectopic lenses is reported. Microspherophakia in cri-du-chat syndrome has not been previously described. The congenital cataracts were inherited from

Received for publication 27 September 1982 Accepted for publication 8 November 1982. his mother who had a balanced 5;13 trans? location; the two events are considered to be? coincidental and a possible 'position effect' was excluded, since the other members of her family" with congenital cataracts, were chromosomallyo normal. This is the fourth case reported where familial cri-du-chat syndrome involves chromo- $\overrightarrow{\mathbb{D}}$ somes $5 p$ and $13 q$. 


\section{Case report}

The proband was the product of the first pregnancy of a 25-year-old mother and a 27-year-old father. The pregnancy was uneventful and delivery was at 39 weeks' gestation. There was no history of maternal infections, drug ingestion, or irradiation during the pregnancy.

The family history is significant in that the father had had postinfectious optic neuropathy since the age of 16 and the mother had congenital nuclear cataracts, with best corrected visual acuity 20/400 in each eye separately. Several maternal relatives had the same cataracts (fig 1).

Birth weight was $2700 \mathrm{~g}$ (between the 10th and 50 th centile), length was $50 \mathrm{~cm}$ (50th centile), head
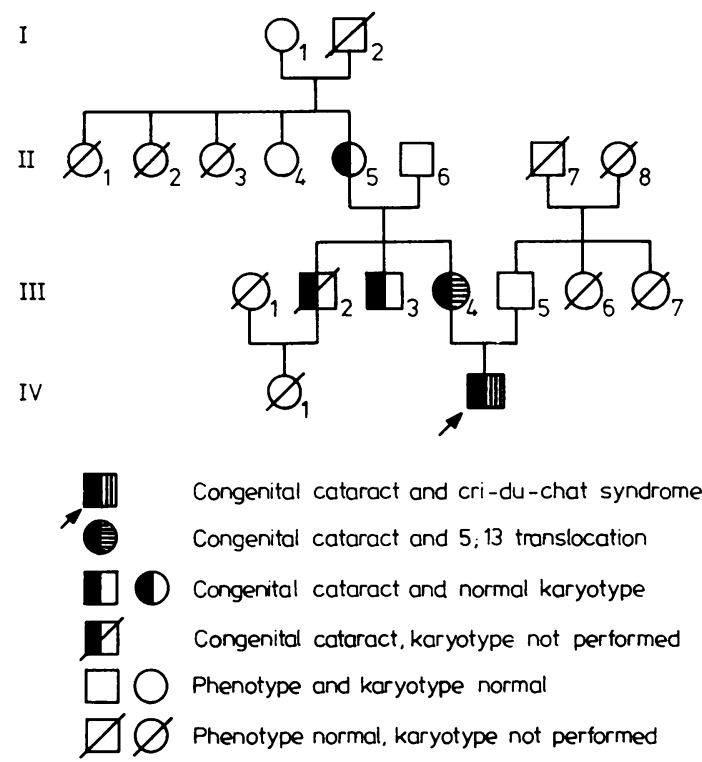

FIG 1 Pedigree of the family. circumference was $35 \mathrm{~cm}$ (50th centile), and the Apgar score was 7 at 1 minute. Physical examination at 1 month of age revealed (fig 2): a high pitched mew-like cry, a round and thin face, epicanthal folds, slight downward slanting eyes, bilateral cataract, flat nasal bridge and philtrum, low set ears, high arched palate, microretrognathia, hypotonia, clinodactyly of the fifth fingers, partial syndactyly of the second and third toes bilaterally, and increased distance between the first and second toes bilaterally. During the neonatal period he had feeding difficulties associated with poor sucking.

Re-examination at 8 months of age showed a length of $65 \mathrm{~cm}$ (less than the $3 \mathrm{rd}$ centile), weight $4450 \mathrm{~g}$ (less than the $3 \mathrm{rd}$ centile), and head circumference $39 \mathrm{~cm}$ (less than the $3 \mathrm{rd}$ centile). He had the physical features of the cri-du-chat syndrome, and also a generalised hypotonia and hyporeflexia. He could not make sounds, roll over, control his head, sit briefly even with support of the pelvis, or transfer objects from hand to hand.

Repeated biomicroscopic examination of the eyes following pupillary dilation (at 1 week and 1,4 , and 6 months of age) showed nuclear cataract, microspherophakia, and probably ectopic lenses bilaterally. The latter finding could not be confirmed because, even after the use of the most potent mydriatics in combination (atropine $0.25 \%$, phenylnephrine $5 \%$, cyclopentolate $2 \%$, and tropicamide $1 \%$, only partial pupillary dilation was obtained. At 8 months of age the 'methacholine test' was performed and the pupil constricted within 15 minutes after one drop of $2.5 \%$ methacholine was placed on the cornea. The ocular fundi could not be examined because of the central total opacity of the lenses (fig 3).

Titres for rubella, toxoplasmosis, and CMV viruses were negative. Radiographs of the skull, heart, bones, and upper gastrointestinal tract were normal. However, a retrograde cystourethrogram demonstrated a second grade vesicoureteral reflux.

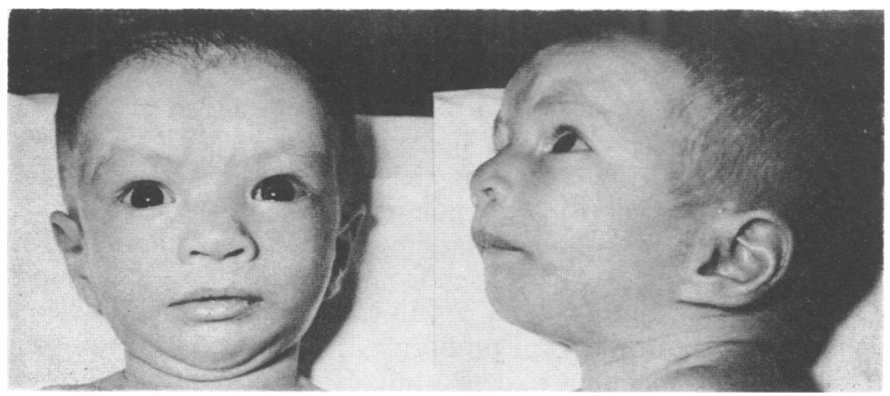

FIG 2 The proband at 1 month of age. 


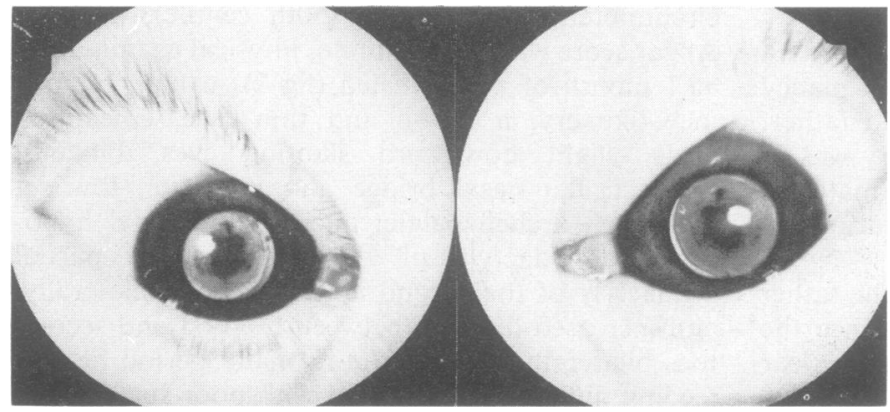

FIG 3 The proband's nuclear cataracts.

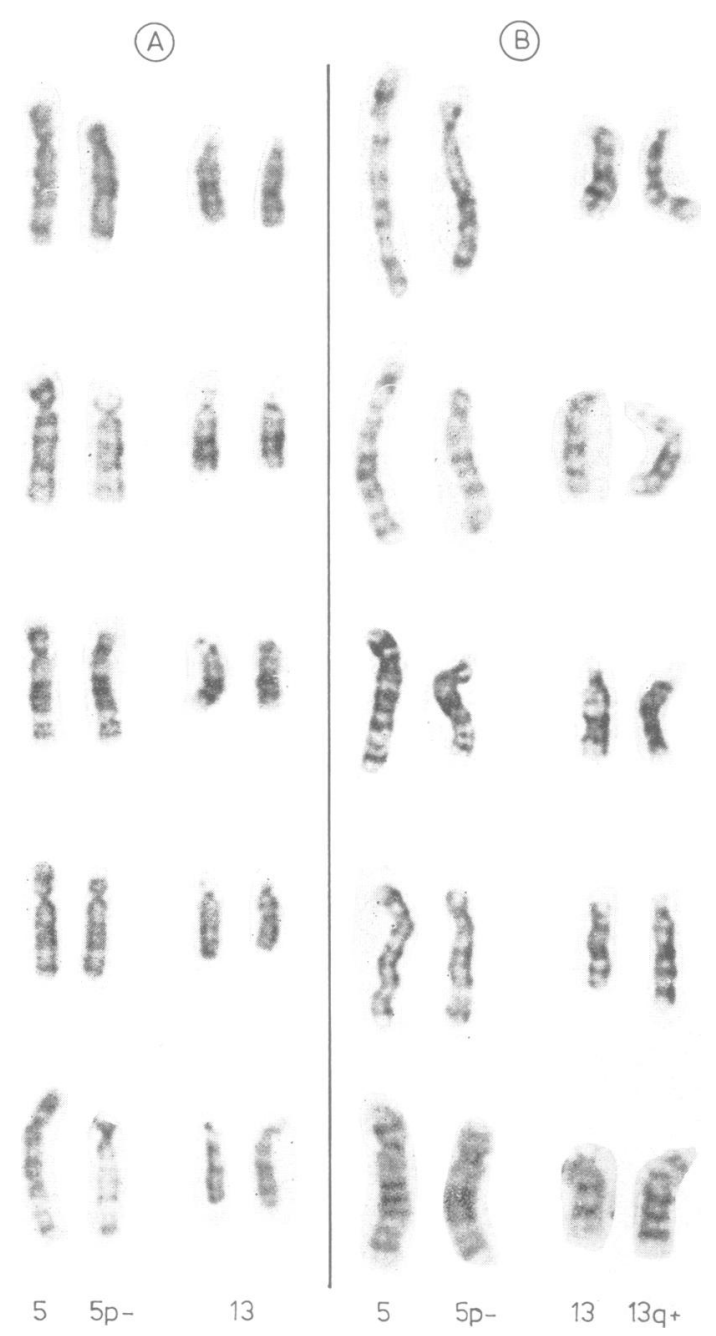

FIG 4 Partial karyotypes of the proband $(A)$ and his mother $(B)$.

\section{DERMATOGLYPHS}

The proband had a unilateral simian crease with ulnar termination on his right palm, a Sidney crease on his left palm, bilateral distally located axial triradii $\left(t^{\prime}\right)$, and whorl patterns on all fingers $\overrightarrow{ }$ and on all toes. His parents had unremarkable dermatoglyphs.

CYTOGENETICS

Chromosome studies using GTG banding were $\stackrel{\infty}{\omega}$ performed on cultured peripheral blood cells and $\square$ fibroblasts from the proband and several members of his family (fig 1). The proband (IV-2) was monosomic for the terminal portion of the short arm of one chromosome 5 (p14 $\rightarrow$ pter). The mother (III 4$) \stackrel{\circ}{\frac{}{D}}$ carried a translocation $(5 ; 13)(\mathrm{p} 14 ; \mathrm{q} 33)$. Therefore, the karyotype of the proband was $46, \mathrm{XY}, \operatorname{der}(5)$, 응 $\mathrm{t}(5 ; 13)(\mathrm{p} 14 ; \mathrm{q} 33)$ mat (fig 4).

The proband's father (III.5) and maternal relatives (III $\cdot 3, \mathrm{II} \cdot 5, \mathrm{II} \cdot 6, \mathrm{II} \cdot 4, \mathrm{I} \cdot 1)$ were shown to have normal chromosomes.

\section{Discussion}

The clinical delineation of the cri-du-chat syndrome was first established by Lejeune et al in $1963 .{ }^{1}$ One year later it was proven to be associated with a partial deletion of one chromosome 5 by German $\frac{D}{0}$ et al. ${ }^{2}$ Howard in $1972^{3}$ studied the ocular abnormalities in seven cases of cri-du-chat syndrome, $N$ but was unable to find a case with cataracts or N microspherophakia. Niebuhr in $1978^{4}$ reviewed data $N$ on 331 cases and the ocular findings in cri-du-chat $\omega$ syndrome were: epicanthal folds $(223 / 252)$, antimongoloid slanting $(144 / 208)$, strabismus $(87 / 156)$, cataract (6), and optic nerve atrophy (16/83).

The proband had most of the common clinical features of the syndrome, since the critical midportion of band $5 \mathrm{p} 15^{5}$ is contained in the deleted $\overrightarrow{\mathbb{D}}$

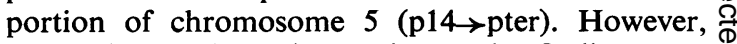

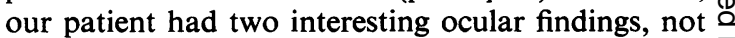


previously reported: bilateral microspherophakia and probably bilateral ectopic lenses. It should be noted, however, that the proband's congenital nuclear cataracts were inherited from his mother and may have no connection with the syndrome. According to the pedigree (fig 1), the cataracts appeared for the first time (de novo) in the maternal grandmother, who transmitted it to all her children by a presumed autosomal mode of inheritance.

The proband had a positive 'methacholine test', which is considered by Howard ${ }^{3}$ to be "specific in establishing the diagnosis in the cri-du-chat syndrome". This reaction of the pupil to methacholine, in addition to its considerable resistance to mydriatics, suggests a possible defective structure of the dilator muscle of the pupil in our proband.

The proband's $5 \mathrm{p}$ - was transmitted from the mother who is a balanced translocation carrier $(5 p ; 13 q)$. This is the fourth familial cri-du-chat case to be reported with a translocation involving the short arm of chromosome 5 and the long arm of chromosome 13.5 The total frequency of familial cri-du-chat cases is $12.1 \%$, out of which $11.2 \%$ is the estimated frequency of familial translocation.

Cytogenetic investigation of the proband's maternal relatives in three generations showed that the translocation $5 ; 13$ in the mother was de novo. The normal karyotypes observed in her relatives with cataracts exclude any relationship between the chromosomal defect and the cataracts.

The authors thank the medical and nursing staff of the Neonatal Unit of the Second Department of Pediatrics for their help and co-operation, and Miss Maria Kouvari for her skilled laboratory assistance.

\section{References \\ 1 Lejeune J, Lafourcade J, Berger R, et al. Trois cas de deletion partielle du bras court d'un chromosome 5 . CR Acad Sci (D) (Paris) 1963;257:3098-102. \\ 2 German J, Lejeune J, McIntyre MN, de Grouchy J. Chromosomal autoradiography in the cri-du-chat syndrome. Cytogenetics $1964 ; 3: 347-52$. \\ 3 Howard RO. Ocular abnormalities in the cri-du-chat syndrome. Am J Ophthalmol 1972;73:949-54. \\ 4 Niebuhr E. The cri-du-chat syndrome. Hum Genet 1978; 44:227-75. \\ 5 Niebuhr E. Cytological observations in 35 individuals with a 5 p - karyotype. Hum Genet $1978 ; 42: 143-56$.}

Correspondence and requests for reprints to Dr Sofia Kitsiou-Tzeli, 51 Kousidou Street, Athens 624 , Greece.

\title{
Phenazopyridine induced methaemoglobinaemia associated with decreased activity of erythrocyte cytochrome $b_{5}$ reductase
}

\author{
JENNIFER S DALY, DONALD E HULTQUIST, AND \\ DONALD L RUCKNAGEL \\ Departments of Internal Medicine, Biological Chemistry, and Human Genetics, University of Michigan \\ Medical Center, Ann Arbor, Michigan 48109, USA.
}

SUMMARY A 25-year-old woman taking usual doses of phenazopyridine developed her third clinically significant episode of cyanosis. Life threatening methaemoglobinaemia was documented and was treated with methylene blue. The patient and several members of her family showed decreased activities of erythrocyte NADH-cytochrome $b_{5}$ reductase, predisposing them to the development of clinically significant methaemoglobinaemia when challenged with oxidant drugs.

Phenazopyridine is a commonly used urinary

Received for publication 13 October 1982. Accepted for publication 11 November 1982. analgesic. Methaemoglobinaemia is a rare side effect of the drug, first reported by Crawford $e t$ al ${ }^{1}$ in 1951 in an infant. Since then 11 cases have been reported, most associated with ingestion of many times the usual therapeutic dose. Only two cases have been reported with standard dosages, ${ }^{2}$ and these occurred in patients with mild renal insufficiency. In none of the reported cases has an abnormality of erythrocyte cytochrome $b_{5}$ reductase (NADH-methaemoglobin reductase) activity been documented. Decreased activity of this enzyme has been reported in subjects who are especially susceptible to toxic methaemoglobinaemia secondary to ingestion of oxidant drugs. ${ }^{3} 4$ We report a case of life threatening methaemoglobinaemia in a patient with decreased reductase activity after ingestion of near-therapeutic amounts of phenazopyridine. 